\title{
Catalyst
}

\section{Zach Murphy}

Catalyst (noun) - A person or thing that precipitates an event or change. (http:// www.dictionary.com/browse/catalyst)

Some journeys begin with a very obvious start. Vacations, for example, usually start when you walk out the door, passport in hand, locking the door with a deliberate turn as if to say: “I'm leaving and I'm going to be gone for a bit". Other journeys start well before we actually know we begin them, even if we fail to realise it in the moment.

My journey through the EqualBITE experience aligns closely to this second type. Maybe I began this great adventure when I was a kid, my mother teaching me about judgement and how people are simply people. Maybe it began as my siblings came into the world, two boys and two girls, creating, as I see it, a perfect balance. Maybe it was none of those, or a combination of those and many many more. Regardless where this journey began, I am on it now, and I am fully and completely committed.

I went to a workshop on gender equality. My wandering search for the room where the workshop was being held was uncomfortable, but not nearly as uncomfortable as walking into the room. Despite the topic of equality, I felt incredibly out of place. I was the only student in the room, the youngest, and one of only two men, the other being a member of staff. All of these factors combined to trigger my self-limiting beliefs about gender, age and status. To calm my nerves and discomfort, I methodically pulled out a notebook, my computer and a pen. Slowly I made more work out of opening a blank document and writing a few titles across the top of the page, avoiding eye contact and conversation. I was uncomfortable. I did not belong. As the workshop started, I did my best to listen, quieting my inner voice, which was telling me to get up and walk away. Despite this challenge, I relied on my most powerful coping mechanisms: responsibility and hard work. I was in that room because of my sense of responsibility for creating gender equality in the classroom and beyond. When the writing started I was able to immerse myself in the work and even managed to swallow the lump in my throat in order to share my experience and narrative.

The writing was powerful for me. I realised that I did have experience relating to gender equality, and that I wanted to be an agent for positive change. My original recipe highlighted the feeling that I had no voice because other people were just too loud with theirs.

A year and a recipe later (see Allies in the classroom), I have realised that the EqualBITE workshop was my catalyst. The journey that started years before moved into full realisation: I have a voice. Despite many people in the community standing on a mountain top and beating their drum, I have a voice.

Following on from the workshop I have been gifted with incredible feedback, powerful conversation, and most importantly belief that what I do matters. EqualBITE has been a catalyst in my life and for the people I am able to influence in a positive way. I believe that the only way we can find equality is if everyone wins, no matter their age, ethnicity, gender, sex or orientation.

I challenge you to find your catalyst, enlist the help of others, have courage and be kind. With kindness and courage your voice will be heard. 


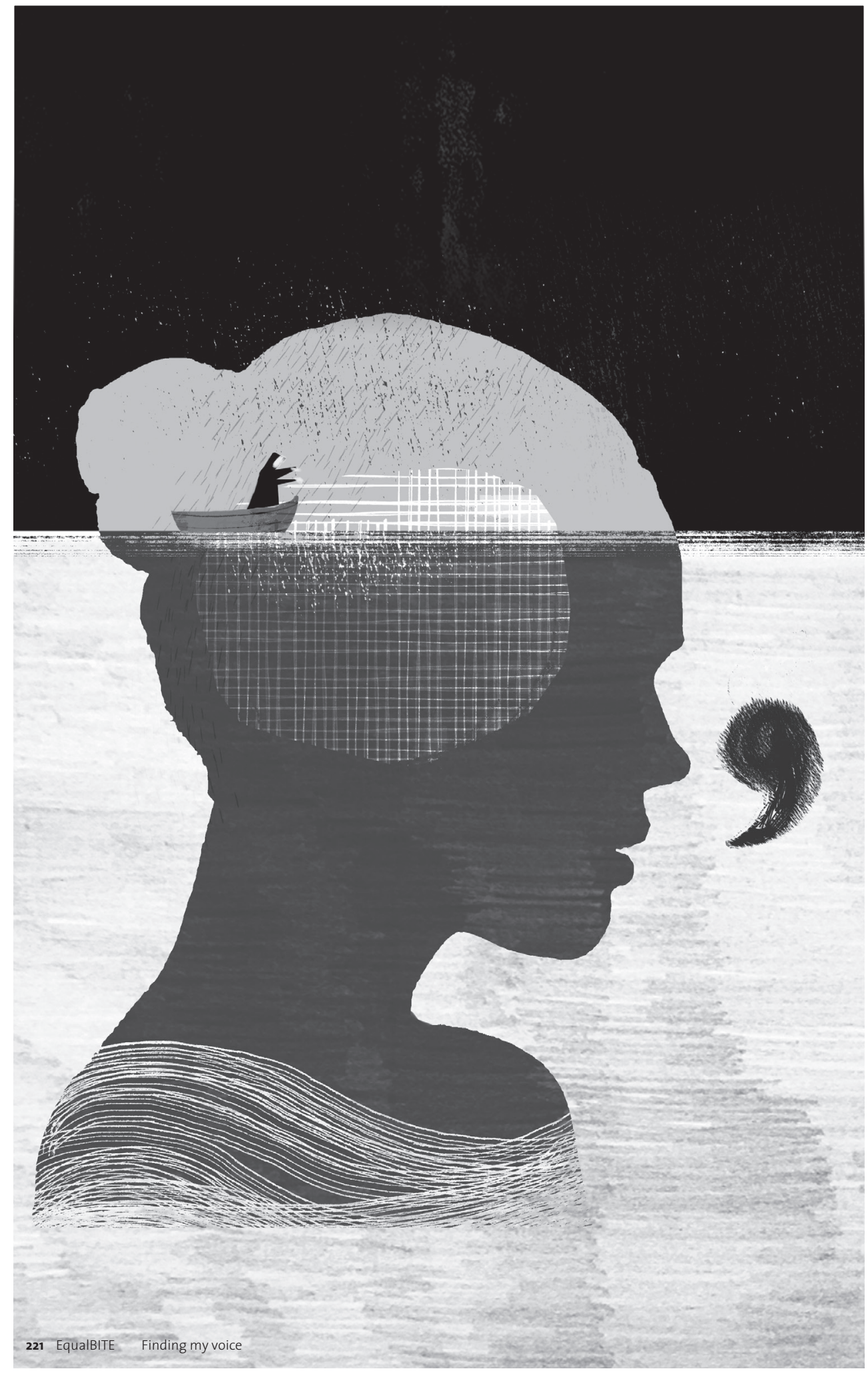

Zach Murphy - 9789463511438 